\title{
Relief for tired T cells
}

DOI:

10.1038/nri1945

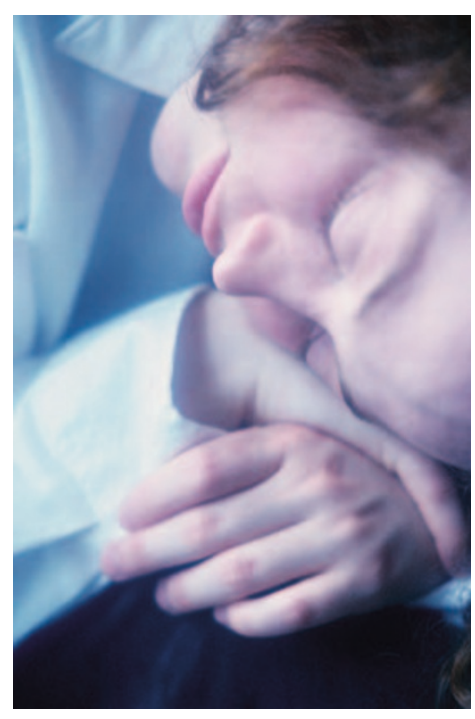

Earlier this year, researchers reported that virus-specific $\mathrm{CD}^{+} \mathrm{T}$ cells in mice with chronic viral infection have an exhausted phenotype that is characterized by expression of large amounts of the inhibitory receptor programmed cell death 1 (PD1). In a concerted effort by two groups, these findings have now been extended to humans.

In these two new studies, researchers used MHC class I tetramers complexed with HIV-derived peptide epitopes to characterize virus-specific $\mathrm{T}$ cells in patients with chronic HIV infection. Both papers reported that PD1 expression was significantly upregulated by HIV-specific (tetramer-positive) $\mathrm{CD}^{+} \mathrm{T}$ cells in untreated HIVinfected individuals compared with treated HIV-infected individuals. Moreover, longitudinal analysis of individuals before and after therapy with antiretroviral agents showed that PD1 expression correlated with viral load. This indicates that the presence of large amounts of viral antigen in individuals with chronic HIV infection might drive continuous high-level expression of PD1 by virus-specific T cells.

Consistent with previous reports, HIV-specific CD8 ${ }^{+} \mathrm{T}$-cell function in individuals with chronic HIV infection (either untreated or treated with antiretroviral agents) was shown to be impaired, with these T cells having a reduced capacity to produce cytokines and proliferate. In both studies, this impaired or 'exhausted' functional phenotype was shown to correlate with high PD1 expression.

Next, both groups asked whether this functional impairment could be reversed by blocking the interaction of PD1 with its ligand (PDL1), as Barber and colleagues had previously shown for mouse T cells (see Further Reading). Indeed, incubation of peripheral-blood mononuclear cells with PDL1-specific antibody following stimulation with HIVderived peptides restored the proliferative capacity of these T cells, as indicated by increased numbers of tetramer-positive $\mathrm{CD}^{+} \mathrm{T}$ cells. The production of cytokines and effector molecules, such as interferon- $\gamma$, tumour-necrosis factor and granzyme $\mathrm{B}$, by $\mathrm{HIV}$-specific $\mathrm{CD}^{+}$ $\mathrm{T}$ cells was also increased in the presence of PDL1-specific antibody compared with stimulation with HIV-derived peptides alone.

Day et al. went on to show that $\mathrm{CD}^{+} \mathrm{T}$ cells, similar to $\mathrm{CD} 8^{+} \mathrm{T}$ cells, are functionally impaired in individuals with chronic HIV infection and that the function of these $\mathrm{T}$ cells could similarly be restored following blockade of the PD1-signalling pathway.

Whether blockade of the PD1-sig- nalling pathway to restore exhausted $\mathrm{T}$ cells is a realistic treatment approach for the effective control of viraemia in patients with chronic HIV infection awaits further study. Lucy Bird

ORIGINAL RESEARCH PAPERS Day, C. L. et al. PD-1 expression on HIV-specific T cells is associated with T-cell exhaustion and disease progression. Nature 20 Aug 2006 (doi:10.1038/ nature05115) | Trautmann, L. et al. Upregulation of PD-1 expression on HIV-specific CD8 ${ }^{+} T$ cells leads to reversible immune dysfunction. Nature Med. 20 Aug 2006 (doi:10.1038/nm1482) FURTHER READING Barber, D. L. et al. Restoring function in exhausted CD8 T cells during chronic viral infection. Nature 439, 682-687 (2006) 